\title{
Effect of age on long-term outcomes after stroke with atrial fibrillation: a hospital-based follow-up study in China
}

\author{
Tao Wang ${ }^{1}$, Bin Li ${ }^{1}$, Hongfei Gu${ }^{1}$, Yongzhong Lou ${ }^{1}$, Xianjia Ning ${ }^{2,3,4}$ Jinghua Wang $^{2,3,4}$ \\ and Zhongping An ${ }^{5}$ \\ ${ }^{1}$ Department of Neurology, Tianjin Haibin People's Hospital, Tianjin, China \\ ${ }^{2}$ Department of Neurology, Tianjin Medical University General Hospital, Tianjin, China \\ ${ }^{3}$ Department of Epidemiology, Tianjin Neurological Institute, Tianjin, China \\ ${ }^{4}$ Tianjin Neurological Institute, Key Laboratory of Post-Neuroinjury Neuro-Repair and Regeneration in Central Nervous \\ System, Ministry of Education and Tianjin City, Tianjin, China \\ ${ }^{5}$ Department of Neurology, Tianjin Huanhu Hospital, Tianjin, China \\ Correspondence to: Bin Li, email: libin_1971_2008@sina.com
}

Zhongping An, email: tjhhazp@sina.com

Xianjia Ning, email: xjn0906@163.com

Keywords: ischemic stroke, atrial fibrillation, outcomes, risk factors, age

Received: October 27, $2016 \quad$ Accepted: February 06, $2017 \quad$ Published: February 25, 2017

Copyright: Wang et al. This is an open-access article distributed under the terms of the Creative Commons Attribution License 3.0 (CC BY 3.0), which permits unrestricted use, distribution, and reproduction in any medium, provided the original author and source are credited.

\section{ABSTRACT}

Atrial fibrillation (AF) is an established predictor of poor outcomes after stroke. We aimed to assess the effect of age on outcomes at 1 year and 3 years in stroke patients with AF. We recruited acute ischemic stroke patients with AF between January 2006 and September 2014 in Tianjin, China. Clinical features and outcomes at 1 year and 3 years after stroke were compared between younger group and elderly group. Overall, 951 consecutive stroke patients with AF were included in this study. There was a higher mortality and dependency rate in the elderly group than in the young group at both 1 and 3 years after stroke. Recurrence rates were significantly higher in the elderly group than in the young group at 3 years after stroke. The higher risks of mortality and dependency in elderly patients remained unchanged, but disappeared in recurrence rates after adjusting for stroke subtype, severity, risk factors, and lifestyle. These findings suggest that it is crucial to highlight the treatment of elderly stroke patients with AF in order to reduce poor outcomes and to reduce the burden of AF in China.

\section{INTRODUCTION}

Stroke is the leading cause of death and disability in both developed and developing countries worldwide [1-3]. The incidence of stroke has declined or plateaued in developed countries [4-6], but it has dramatically increased in developing countries, especially in China [79]. Although there had been a trend toward the occurrence of incident stroke later in life in the past two decades, the proportion of stroke burden is greater overall in individuals $<75$ years than in those who are older, especially in lowincome and middle-income regions [10].
Atrial fibrillation (AF) is the most common sustained cardiac arrhythmia, which is an established risk factor for ischemic stroke [11,12]. The prevalence of AF in the general population increases substantially with age, ranging from $0.1 \%$ in those aged $<55$ years to $9 \%$ in those aged $\geq 80$ years [13]. Although there is a low prevalence of AF in China, the disease burden of AF-related stroke is great due to the aging population.

Age is the most important non-modifiable risk factor for stroke $[14,15]$, and elderly patients experiencing stroke generally have poor functional outcomes afterwards [16-18]. Moreover, patients with AF-associated stroke have higher mortality than do stroke patients without AF, 
with rates between $30.5 \%$ and $63.0 \%$ at 12 months after stroke $[19,20]$. However, the long-term outcomes and risk factors for these outcomes in patients with AF-associated stroke in China are uncertain. We therefore aimed to assess the effect of age on outcomes and the risk factors for these outcomes among patients with AF-associated stroke in China.

\section{RESULTS}

A total of 11,330 consecutive patients with ischemic stroke treated at three large hospitals in Tianjin during the study period were registered for this study. Of these, 951 patients had AF. Outcomes were assessed for 834 patients with AF-associated stroke at the 1-year follow-up, after excluding 55 patients lost to follow-up and 62 patients with a follow-up period of $<1$ year; the response rate for follow-up was thus $93.8 \%$. Outcomes for 635 patients were assessed at the 3-year follow-up, after excluding 56 patients lost to follow-up and 260 patients with a followup period of $<3$ years; the response rate for this follow-up was thus $91.9 \%$ (Figure 1).

\section{Differences in clinical features between groups}

Overall, 951 patients with AF-associated stroke were included in this study; there were 423 patients (44.5\%) in the elderly group. Worse neurological function was observed in the elderly group than in the younger group; the elderly group had higher NIHSS and mRS scores and

\section{0 acute ischemic stroke patients were rectuted to this study, from January 2006 to September 2014.}

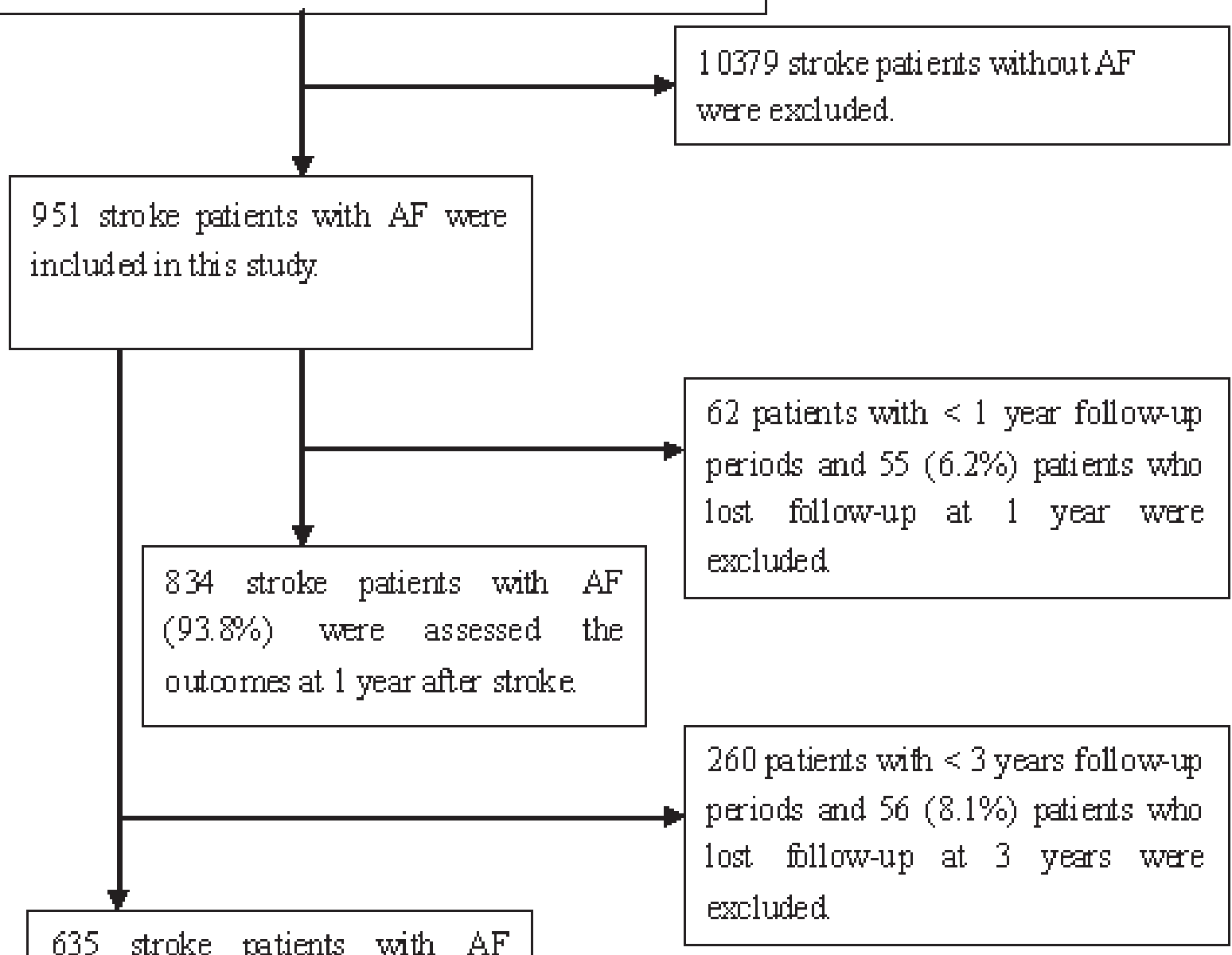

Figure 1: Flow chart of Participants 
Table 1: Clinical features and previous history of diseases in patients with ischemic stroke and AF by age group

\begin{tabular}{|c|c|c|c|}
\hline Characteristics & Young group & Elderly group & $P$ \\
\hline Cases, n (\%) & $528(55.5)$ & $423(44.5)$ & - \\
\hline Gender, n (\%): & & & 0.271 \\
\hline Men & $296(57.1)$ & $222(42.9)$ & \\
\hline Women & $232(53.6)$ & $201(46.4)$ & \\
\hline OCSP classification, $\mathrm{n}(\%)$ : & & & 0.195 \\
\hline Partial anterior circulation infarct & $327(62.5)$ & $236(56.3)$ & \\
\hline Total anterior circulation infarct & $91(17.4)$ & $88(21.0)$ & \\
\hline Lacunar infarct & $9(1.7)$ & $12(2.9)$ & \\
\hline Posterior circulation infarct & $96(18.4)$ & $83(19.8)$ & \\
\hline Stroke severity, n (\%): & & & 0.691 \\
\hline Mild & $211(40.0)$ & $162(38.3)$ & \\
\hline Moderate & $145(27.5)$ & $112(26.5)$ & \\
\hline Severe & $172(32.6)$ & $149(35.2)$ & \\
\hline \multicolumn{4}{|l|}{ Neurological function: } \\
\hline NIHSS & $10(15)$ & $12(14)$ & 0.005 \\
\hline $\mathrm{BI}$ & $30(60)$ & $20(50)$ & 0.001 \\
\hline $\mathrm{mRS}$ & $4(3)$ & $4(2)$ & 0.002 \\
\hline \multicolumn{4}{|l|}{ Laboratory examination: } \\
\hline Total cholesterol: & $4.91(1.18)$ & $4.84(1.24)$ & 0.434 \\
\hline Triglyceride: & $1.35(0.89)$ & $1.26(1.03)$ & 0.162 \\
\hline High density lipoprotein cholesterol: & $1.15(0.40)$ & $1.16(0.29)$ & 0.526 \\
\hline Low density lipoprotein cholesterol: & $3.08(0.96)$ & $2.97(0.96)$ & 0.093 \\
\hline Fasting glucose & $6.55(2.68)$ & $6.64(2.86)$ & 0.677 \\
\hline Glycosylated hemoglobin & $6.34(0.96)$ & $6.29(1.27)$ & 0.671 \\
\hline
\end{tabular}

lower BI. However, there were no significant differences in stroke severity and subtype between the age groups (all $P>0.05$ ). Moreover, the levels of TC, TG, HDL-C, LDL-C, FG, and $\mathrm{HbAlc}$ were not significantly different between the two groups (Table 1).

\section{Differences in stroke risk factors and lifestyle factors between groups}

There were no obvious differences in the prevalence of hypertension, DM, dyslipidemia, obesity, and current smoking, but there was a higher frequency of alcohol consumption in the younger group than in the elderly group $(10.4 \%$ vs. $5.0 \%, P=0.002)$ (Table 2$)$.

\section{Differences in outcomes at 1 and 3 years after stroke between groups}

Table 3 shows that poor outcomes were observed in the elderly group. The mortality rate was higher in the elderly group than in the young group (OR [95\% CI], 1.86 [1.36-2.54] 1 year after stroke, and 2.54 [1.83-3.53] at 3 years after stroke, all $P<0.001)$. Similar trends were observed for dependency rates (OR [95\% CI], 1.85 [1.40$2.44]$ at 1 year after stroke, and $2.80[1.81-4.35]$ at 3 years after stroke, all $\mathrm{P}<0.001)$. Recurrence rates were significantly higher in the elderly group than in the young group at 3 years after stroke (OR [95\% CI], 1.76 [1.14 $2.72], P<0.001)$. However, the significant difference in recurrence rates disappeared after adjusting for stroke subtype, severity, risk factors, and lifestyle factors. The OR $(95 \% \mathrm{CI})$ for mortality rate was $1.98(1.39-2.82, P<$ $0.001)$ at 1 year and $2.95(2.02-4.32, P<0.001)$ at 3 years; the corresponding values for dependency rates were 1.79 $(1.33-2.42, P<0.001)$ and $3.06(1.90-4.93, P<0.001)$, respectively.

\section{DISCUSSION}

This is the first report on the effects of age on longterm outcomes among stroke patients with $\mathrm{AF}$ in China. We compared differences in clinical features, conventional stroke risk factors, and outcomes at 1 year and 3 years after stroke between younger and elderly patients.

Previous studies indicated that stroke patients with $\mathrm{AF}$ were less likely than stroke patients without $\mathrm{AF}$ to have conventional risk factors for stroke, including hypertension, current smoking and alcohol consumption habits, and diabetes [21, 22]. Other studies reported significant differences in the frequency of conventional stroke risk factors [23]. The present study focused 
Table 2: Clinical features and previous history of diseases in patients with ischemic stroke and AF by age group

\begin{tabular}{|l|c|c|c|}
\hline \multicolumn{1}{|c|}{ Risk Factors } & Young group & Elderly group & $P$ \\
\hline Hypertension & $340(64.4)$ & $276(65.2)$ & 0.784 \\
\hline Diabetes & $144(27.3)$ & $94(22.2)$ & 0.074 \\
\hline Dyslipidemias & $136(25.8)$ & $100(23.6)$ & 0.452 \\
\hline Artery stenosis & $85(16.1)$ & $87(20.6)$ & 0.075 \\
\hline Obesity & $73(13.8)$ & $67(15.8)$ & 0.384 \\
\hline Current smoking & $129(24.4)$ & $98(23.2)$ & 0.650 \\
\hline Alcohol consumption & $55(10.4)$ & $21(5.0)$ & 0.002 \\
\hline
\end{tabular}

Table 3: Outcomes and odds ratios 1 year and 3 years after stroke among patients with AF by age group

\begin{tabular}{|l|c|c|c|c|c|c|}
\hline \multirow{2}{*}{ Outcomes } & \multirow{2}{*}{ Young group } & \multirow{2}{*}{ Elderly group } & \multicolumn{2}{c|}{ Univariate analysis } & \multicolumn{2}{c|}{ Multivariate analysis } \\
\cline { 5 - 7 } & & & OR(95\%CI) & $\boldsymbol{P}$ & OR(95\%CI) & $\boldsymbol{P}$ \\
\hline 1 year: & & & & & \\
\hline Mortality & $98(20.5)$ & $118(32.4)$ & $1.86(1.36,2.54)$ & $<0.001$ & $1.98(1.39,2.82)$ & $<0.001$ \\
\hline Dependency & $224(47.0)$ & $226(62.1)$ & $1.85(1.40,2.44)$ & $<0.001$ & $1.79(1.33,2.42)$ & $<0.001$ \\
\hline Recurrence & $81(21.3)$ & $62(25.6)$ & $1.27(0.87,1.86)$ & 0.214 & $1.16(0.78,1.71)$ & 0.475 \\
\hline 3 years: & & & & & & \\
\hline Mortality & $104(29.7)$ & $145(51.8)$ & $2.54(1.83,3.53)$ & $<0.001$ & $2.95(2.02,4.32)$ & $<0.001$ \\
\hline Dependency & $257(73.4)$ & $248(88.6)$ & $1.76(1.14,2.72)$ & $<0.001$ & $1.57(0.98,2.51)$ & $<0.001$ \\
\hline Recurrence & $122(52.1)$ & $90(65.7)$ & $2.80(1.81,4.35)$ & $<0.001$ & $3.06(1.90,4.93)$ & 0.011 \\
\hline
\end{tabular}

on patients with stroke and AF and showed that the prevalence of hypertension, diabetes, dyslipidemias, arterial stenosis, obesity, and current smoking were not significantly different between the two age groups. However, the frequency of alcohol consumption was greater in the younger group than in the elderly group. At the same time, we did not observe any differences in the levels of TC, TG, HDL-C, LDL-C, FG, and HbA1c between the younger and elderly groups. These results indicate that there is not an obvious relationship between age and the prevalence of conventional risk factors in stroke patients with AF.

Moreover, there remains controversy regarding differences in outcomes after stroke between patients with and without AF in the elderly, especially with respect to the long-term outcomes for elderly stroke patients with AF. Many studies have demonstrated that elderly stroke patients were more likely to have poor outcomes after acute ischemic stroke, including increased short-term and long-term mortality rates, dependency rates, and risk of stroke recurrence [15-19, 24, 25]. Previous studies have similarly reported that AF is associated with higher mortality rates [26-29], higher recurrence rate [26, 30], and a markedly increased dependency in stroke patients with AF [31]. However, long-term outcomes for elderly stroke patients with AF remain uncertain, and there is in particular a relative paucity of longitudinal data that assess long-term outcomes after stroke in China. In the present study, we found that mortality and dependency rates were significantly higher in the elderly group than in the younger group at both 1 and 3 years after stroke in patients with AF. There was a higher observed recurrence rate at 3 years after stroke in the elderly group than in the younger group. One-third of patients in the younger group and more than one-half of patients in the elderly group had died by 3 years after stroke onset. Moreover, most survivors experienced dependency (73.4\% in the younger group and $88.6 \%$ in the elderly group) and recurrence $(52.1 \%$ in the younger group and $65.7 \%$ in the elderly group) 3 years after stroke onset. These trends did not change after adjustment using clinical features, risk factors, and lifestyle factors as covariates. There was an incremental increase in the risk of mortality and dependency, but not recurrence. Suboptimal treatment for AF in Chinese patients compared with that for Western patients with AF may explain the poor outcomes after stroke in elderly patients [32-34].

Moreover, there were several limitations in this study. First, this study used a local stroke registry, and all patients were recruited from same city; thus, limited 
representation occurred. Second, patients who died before admission to the stroke unit and those lost to follow-up were excluded in this study, so poor outcomes may be underestimated. Third, pre-stroke data were lacking, including treatment and medicine use for AF.

\section{CONCLUSIONS}

In this large hospital-based stroke registry, we compared differences in clinical features, risk factors, and outcomes at 1 and 3 years following AF-associated stroke between younger and elderly patients. There was a higher prevalence of AF in the elderly group than in the younger group. The prevalence of hypertension, DM, dyslipidemia, artery stenosis, obesity, and current smoking were not obviously different between the two groups, but there was a higher frequency of alcohol drinking in the younger group. Poorer long-term outcomes were observed in the elderly group. There was an incremental risk of mortality and dependency at 1 and 3 years after stroke in the elderly group. These findings suggest that elderly stroke patients, especially those with AF, should be targeted for secondary stroke prevention to reduce the burden due to stroke in China.

\section{MATERIALS AND METHODS}

\section{Patient selection}

This was a hospital-based follow-up study using the Stroke Registry System. All consecutive patients with acute ischemic stroke admitted to the stroke unit within 72 hours of stroke onset in three hospitals in Tianjin, China, between January 2006 and September 2014 were recruited to this study. All patients were diagnosed according to World Health Organization criteria confirmed via brain computed tomography (CT) or magnetic resonance imaging (MRI) [35]. Patients experiencing transient ischemic attack were excluded from this study. Trained neurologists selected detailed information for patients with acute ischemic stroke, including ischemic stroke subtype, stroke severity, previous medical history, lifestyle factors, and outcomes at 1 year and 3 years after stroke.

To ensure data quality, three groups of senior trained neurologists (the assessment group, the followup group, and the quality control group) were responsible for determining the nervous system score at admission, for the reexamination (including of neurological score, risk factor management, and directing the treatment and rehabilitation) during follow-up, and a sampled confirmation of $20 \%$ of all patients each month, respectively.

All investigative protocols were approved by the ethics committee of Tianjin Medical University General
Hospital. The methods were carried out in accordance with approved guidelines, and informed consent was obtained from each patient.

\section{Stroke subtypes}

Stroke subtypes, which were classified on admission, included total anterior circulation infarct (TACI), partial anterior circulation infarct (PACI), lacunar infarct (LACI), and posterior circulation infarct (POCI), according to the Oxfordshire Community Stroke Project (OCSP) criteria [36].

\section{Stroke severity}

Stroke severity was categorized into three categories according to the National Institutes of Health stroke scale (NIHSS): mild (NIHSS score $\leq 7$ ), moderate (NIHSS score 8-16), and severe (NIHSS score $\geq 17$ ) [37]. Meanwhile, the Bethel index (BI) and $\mathrm{mRS}$ scores were also recorded on admission.

\section{Stroke risk factors and lifestyle factors}

Risk factors for stroke included hypertension, diabetes mellitus, dyslipidemia, AF, brain-supplied arterial stenosis, and obesity (body mass index $[\mathrm{BMI}] \geq 30 \mathrm{~kg} / \mathrm{m}^{2}$ ). Lifestyle factors included current smoking ( $\geq 1$ cigarette per day for $\geq 1$ year) and alcohol consumption (drinking alcohol at least 1 time per week for 1 year).

The levels of total cholesterol (TC), triglycerides (TG), high-density lipoprotein cholesterol (HDL-C), lowdensity lipoprotein cholesterol (LDL-C), fasting glucose (FG), and glycosylated hemoglobin (HbAlc) were recorded on admission.

\section{Outcomes after stroke}

Outcomes after stroke were described by mortality, recurrence, and dependency at 1 and 3 years after stroke. Outcomes were assessed with both face-to-face and telephone follow-up. Death was defined as all-cause cumulative death in corresponding periods after stroke and was determined based on reports from patients' family members and telephone follow-up. Stroke recurrence was defined as all new-onset vascular events, including stroke, myocardial infarction, and venous thrombosis, 30 days after stroke. Information pertaining to diagnosis and classification of recurrent stroke were obtained from the medical record department in the discharge hospitals. Dependency was defined as an mR score $>2$ [20]. 


\section{Statistical analysis}

All patients with acute ischemic stroke were classified into two groups based on age $(<75$ years and $\geq 75$ years) for analysis. Continuous variables, including age, NIHSS score, BI, mRS score, and TG, TC, HDL-C, LDL-C, FG, and HbA1c levels were presented as mean (standard deviation) or median (range), as appropriate, and were compared between the two groups using the Student t-test or the Mann-Whitney U-test. Dichotomous variables, including stroke subtype, stroke severity, stroke risk factors, and outcomes over different periods after stroke, were presented as numbers (percentages) and were compared with the chi-squared test. Differences in outcomes between the two groups were assessed with a logistic regression analysis. A multivariate analysis was carried out with a logistic regression model to evaluate differences in outcomes over different periods after stroke, with stroke subtype, stroke severity, risk factors, and lifestyle factors as covariates. Data for this analysis were presented as adjusted odds ratios (ORs) with 95\% confidence intervals (CIs). Patients lost to follow-up were excluded from outcome evaluation. All statistical analyses were performed using SPSS version 19.0 (SPSS Inc., Chicago, IL), and a two-tailed $P<0.05$ indicated statistical significance.

\section{ACKNOWLEDGMENTS}

We thank all participants in this system.

\section{CONFLICTS OF INTEREST}

The research was conducted in the absence of any commercial or financial relationships that could be construed as a potential conflict of interest.

\section{FUNDING}

This study was funded by Local Key Project of Binhai New District, Tianjin of China, and The Project of Prevention and Treatment System on Cerebrovascular Disease in Dagang Oilfield, China and Tianjin Health Bureau of Science and Technology Fund Key Projects (contract: KY12, and 2013KG120).

\section{REFERENCES}

1. Carter AM, Catto AJ, Mansfield MW, Bamford JM, Grant PJ. Predictive variables for mortality after acute ischemic stroke. Stroke. 2007; 38:1873-80.

2. Zhang XH, Guan T, Mao J, Liu L. Disparity and its time trends in stroke mortality between urban and rural populations in China 1987 to 2001: changing patterns and their implications for public health policy. Stroke. 2007;
38:3139-44.

3. Lopez AD, Mathers CD, Ezzati M, Jamison DT, Murray CJ. Global and regional burden of disease and risk factors, 2001: systematic analysis of population health data. Lancet. 2006; 367:1747-57.

4. Lloyd-Jones DM, Hong Y, Labarthe D, Mozaffarian D, Appel LJ, Van Horn L, Greenlund K, Daniels S, Nichol G, Tomaselli GF, Arnett DK, Fonarow GC, Ho PM, et al. Defining and setting national goals for cardiovascular health promotion and disease reduction: the American Heart Association's strategic Impact Goal through 2020 and beyond. Circulation. 2010; 121:586-613.

5. Lloyd-Jones D, Adams R, Carnethon M, De Simone G, Ferguson TB, Flegal K, Ford E, Furie K, Go A, Greenlund K, Haase N, Hailpern S, Ho M, et al. Heart disease and stroke statistics - 2009 update: a report from the American Heart Association Statistics Committee and Stroke Statistics Subcommittee. Circulation. 2009; 119:480-6.

6. Redon J, Olsen MH, Cooper RS, Zurriaga O, MartinezBeneito MA, Laurent S, Cifkova R, Coca A, Mancia G. Stroke mortality and trends from 1990 to 2006 in 39 countries from Europe and Central Asia: implications for control of high blood pressure. Eur Heart J. 2011; 32:142431 .

7. Zhao D, Liu J, Wang W, Zeng Z, Cheng J, Liu J, Sun J, Wu Z. Epidemiological transition of stroke in China: twentyone-year observational study from the Sino-MONICABeijing Project. Stroke. 2008; 39:1668-74.

8. Jiang B, Wang WZ, Chen H, Hong Z, Yang QD, Wu SP, $\mathrm{Du} \mathrm{XL}$, Bao QJ. Incidence and trends of stroke and its subtypes in China: results from three large cities. Stroke. 2006; 37:63-8.

9. Wang J, An Z, Li B, Yang L, Tu J, Gu H, Zhan C, Liu B, $\mathrm{Su}$ TC, Ning $X$. Increasing stroke incidence and prevalence of risk factors in a low-income Chinese population. Neurology. 2015; 84: 374-81.

10. Lozano R, Naghavi M, Foreman K, Lim S, Shibuya K, Aboyans V, Abraham J, Adair T, Aggarwal R, Ahn SY, Alvarado M, Anderson HR, Anderson LM, et al. Global and regional mortality from 235 causes of death for 20 age groups in 1990 and 2010: a systematic analysis for the Global Burden of Disease Study 2010. Lancet. 2012; 380:2095-128.

11. Chugh SS, Blackshear JL, Shen WK, Hammill SC, Gersh BJ. Epidemiology and natural history of atrial fibrillation: clinical implications. J Am Coll Cardiol. 2001; 37: 371-8.

12. Wolf PA, Abbott RD, Kannel WB. Atrial fibrillation as an independent risk factor for stroke: the Framingham Study. Stroke. 1991; 22:983-8.

13. Deng YX, Wang YL, Gao BQ, Wang CX, Zhao XQ, Liu LP, Wang AX, Zhou Y, Liu GF, Du WL, Zhang N, Jing J, Meng X, et al. Age Differences in Clinical Characteristics, Health care, and Outcomes after Ischemic Stroke in China. CNS Neuroscience \& Therapeutics. 2012; 18: 819-26. 
14. World Health Organization. MONICA project (Monitoring Trends and Determinants in Cardiovascular Disease): a major international collaboration: WHO MONICA Project Principal Investigators. J Clin Epidemiol. 1988; 41:105-14.

15. Rothwell PM, Coull AJ, Silver LE, Fairhead JF, Giles MF, Lovelock CE, Redgrave JN, Bull LM, Welch SJ, Cuthbertson FC, Binney LE, Gutnikov SA, Anslow P, et al. Population-based study of event-rate, incidence, case fatality, and mortality for all acute vascular events in all arterial territories (Oxford Vascular Study). Lancet. 2005; 366:1773-83.

16. Marini C, Baldassarre M, Russo T, De Santis F, Sacco $\mathrm{S}$, Ciancarelli I, Carolei A. Burden of first-ever ischemic stroke in the oldest old: evidence from a population-based study. Neurology. 2004; 62:77-81.

17. Palnum KD, Petersen P, Sørensen HT, Ingeman A, Mainz J, Bartels P, Johnsen SP. Older patients with acute stroke in Denmark: quality of care and short-term mortality: a nationwide follow-up study. Age Ageing. 2008; 37:90 -5.

18. Fonarow GC, Reeves MJ, Zhao X, Olson DM, Smith EE, Saver JL, Schwamm LH; Get With the GuidelinesStroke Steering Committee and Investigators. Age-related differences in characteristics, performance measures, treatment trends, and outcomes in patients with ischemic stroke. Circulation. 2010; 121:879-91.

19. Saposnik G, Hill MD, O’Donnell M, Fang J, Hachinski V, Kapral MK, Registry of the Canadian Stroke Network for the Stroke Outcome Research Canada (SORCan) Working Group. Variables associated with 7-day, 30-day, and 1-year fatality after ischemic stroke. Stroke. 2008; 39:2318-24.

20. Banks JL, Marotta CA. Outcomes validity and reliability of the modified Rankin scale: implications for stroke clinical trials: a literature review and synthesis. Stroke. 2007; 38:1091-6.

21. Lamassa M, Di Carlo A, Pracucci G, Basile AM, Trefoloni G, Vanni P, Spolveri S, Baruffi MC, Landini G, Ghetti A, Wolfe CD, Inzitari D. Characteristics, Outcome, and Care of Stroke Associated With Atrial Fibrillation in Europe Data From a Multicenter Multinational Hospital-Based Registry (The European Community Stroke Project). Stroke. 2001; 32:392-8.

22. Mizrahi EH, Fleissig Y, Arad M, Adunsky A. Short-term functional outcome of ischemic stroke in the elderly: a comparative study of atrial fibrillation and non-atrial fibrillation patients. Arch Gerontol Geriatr. 2014; 58:121-4.

23. Andrew N, Kilkenny M, Harris D, Price C, Cadilhac DA. Outcomes for people with atrial fibrillation in an Australian national audit of stroke care. Int J Stroke. 2014; 9:270-7.

24. Johnston SC, Gress DR, Browner WS, Sidney S. Short-term prognosis after emergency diagnosis of TIA. JAMA. 2000; 284:2901-6.
25. Kammersgaard LP, Jørgensen HS, Reith J, Nakayama H, Pedersen PM, Olsen TS, Copenhagen Stroke Study. Short- and long-term prognosis for very old stroke patients: Copenhagen Stroke Study. Age Ageing. 2004; 33: 149-54.

26. Lin HJ, Wolf PA, Kelly-Hayes M, Beiser AS, Kase CS, Benjamin EJ, D’Agostino RB. Stroke severity in atrial fibrillation: the Framingham Study. Stroke . 1996; 27: 1760-4.

27. Jørgensen HS, Nakayama H, Reith J, Raaschou HO, Olsen TS. Acute stroke with atrial fibrillation: the Copenhagen Stroke Study. Stroke. 1996; 27:1765-9.

28. Candelise L, Pinardi G, Morabito A. Mortality in acute stroke with atrial fibrillation. Stroke. 1991; 22:169-74.

29. Gustaffson C, Britton M. Pathogenetic mechanism of stroke in non-valvular atrial fibrillation: follow-up of stroke patients with and without atrial fibrillation. J Intern Med. 1991; 230:11-6.

30. Sandercock P, Bamford J, Dennis M, Burn J, Slattery J, Jones L, Boonyakarnkul S, Warlow C. Atrial fibrillation and stroke prevalence in different types of stroke and influence on early- and long-term prognosis (Oxfordshire Community Stroke Project). Br Med J. 1992; 305:1460-5.

31. Karataş M, Dilek A, Erkan H, Yavuz N, Sözay S, Akman N. Functional outcome in stroke patients with atrial fibrillation. Arch Phys Med Arch Phys Med Rehabil. 2000; 81:1025-9.

32. Lalouschek W, Lang W, Müllner M, Vienna Stroke Study Group. Current strategies of secondary prevention after a cerebrovascular event: the Vienna Stroke Registry. Stroke. 2001; 32: 2860-6.

33. Lalouschek W, Lang W, Müllner M, Vienna Stroke Study Group. Clinical characteristics and management of acute stroke in patients with atrial fibrillation admitted to US university hospitals. Neurology. 1997; 48: 1598-604.

34. Lin S, Wu B, Hao ZL, Kong FY, Tao WD, Wang DR, He S, Liu M. Characteristics, treatment and outcome of ischemic stroke with atrial fibrillation in a Chinese hospital-based stroke study. Cerebrovasc Dis. 2011; 31:419-26.

35. World Health Organization Task Force on Stroke and Other Cerebrovascular Disorders: Stroke-1989. Recommendations on stroke prevention, diagnosis, and therapy. Report of the WHO task force on stroke and other cerebrovascular disorders. Stroke. 1989; 20: 1407-31.

36. Bamford J, Sandercock P, Dennis M, Burn J, Warlow C. Classification and natural history of clinically identifiable subtypes of cerebral infarction. Lancet. 1991; 337: 1521-6.

37. Kim JS, Lee KB, Roh H, Ahn MY, Hwang HW. Gender Differences in the Functional Recovery after Acute Stroke. J Clin Neurol. 2010; 6:183-8. 